J. Gen. Appl. MicrobioI.

Vol. 6, No. 4, 1960

\title{
CATABOLISM OF 5-KETOGLUCONIC ACID BY ACETOBACTER SUBOXYDANS
}

\author{
HARUYOSHI MUROOKA, YUKASHI KOBAYASHI \\ and TOSHINOBU ASAI \\ The Institute of Applied Microbiology, University of Tokyo \\ Recieved for publication. Aug. 5, 1960
}

It is well known that glucose is oxidized to 2-ketogluconic acid (2-KGA), 5 -ketogluconic acid (5-KGA) or both of them via gluconic acid by Acetobacter and allied oxidative bacteria. It is considered important to clarify the further oxidative pathways of these ketogluconic acids. Many papers have appeared on the metabolic route of 2 -KGA, while little attention has been paid to the oxidative route of $5-\mathrm{KGA}$, despite the fact that several papers on this subject $(1 \sim 5)$ were published recently. The authors have studied this problem to elucidate metabolic pathway of $5-\mathrm{KGA}$, and it was ascertained that 5-KGA was oxidized in the presence of glucose by intact cell suspension of Acetobacter suboxydans (1). On the oxidation products of 5-KGA, only JACKSON et al. (6) have reported on the formation of L-tartaric, glycolic, formic acids and $\mathrm{CO}_{2}$ by Pseudomonas fluorescens. The present investigations were mainly concerned with isolation and identification of oxidation products from 5 -KGA by $A$. suboxydans as well as with elucidation of the rôles of these compounds in oxidative pathway of 5-KGA for the purpose of clarifying its metabolic pathway.

\section{EXPERIMENTAL}

1) Organism. Acetobacter suboxydans ATCC 621 was used. This strain was maintained for a long time in this laboratory on Koji extract agar slants containing $\mathrm{CaCO}_{3}$.

2) Preparation of intact cell suspension and dried cells. The cells grown on glucose yeast extract agar medium containing $\mathrm{CaCO}_{3}$ in Roux flasks for 48 hours at $30^{\circ} \mathrm{C}$ were harvested and washed three times with distilled water and then suspended in distilled water. Dried cells were prepared by drying the washed cells in vacuo on silica gel.

3) Reaction method. The reaction mixtures containing $50 \mathrm{ml}$ of solution ((a), (b) or (c)) in $500 \mathrm{ml}$ shake flasks were incubated aerobiocally on a reciprocating shaker at $30^{\circ} \mathrm{C}$.

Solution (a)

Intact cell suspension (dry weight, $80 \mathrm{mg}$ ) $20 \mathrm{ml}$

$\mathrm{M} / 10$ Phosphate buffer solution ( $\mathrm{pH} 5.0$ ) $20 \mathrm{ml}$

M/4 K-5-Ketogluconate solution (K-5-ketogluconate, $348.3 \mathrm{mg}$ ) $6 \mathrm{ml}$ 
$\mathrm{M} / 100$ Glucose solution (glucose, $0.7 \mathrm{mg}$ )

Solution (b)

Intact cell suspension (dry weight, $80 \mathrm{mg}$ )

$\mathrm{M} / 10$ Phosphate buffer solution ( $\mathrm{pH} 5.0$ )

$\mathrm{M} / 100$ Glucose solution (glucose, $0.7 \mathrm{mg}$ )

Distilled water

Solution (c)

$\mathrm{M} / 10$ Phosphate buffer solution ( $\mathrm{pH} 5.0$ )

M/4 K-5-Ketogluconate solution (K-5-ketogluconate $348.3 \mathrm{mg}$ ) $6 \mathrm{ml}$

Distilled water

Total volume $50 \mathrm{ml}$

Total volume $50 \mathrm{ml}$

$24 \mathrm{ml}$
$4 \mathrm{ml}$

$$
\begin{array}{r}
20 \mathrm{ml} \\
20 \mathrm{ml} \\
4 \mathrm{ml} \\
6 \mathrm{ml}
\end{array}
$$

$20 \mathrm{ml}$

Total volume $50 \mathrm{ml}$

4) The procedures of paper chromatography used for the detection of reaction products are as follows.

a) Paper chromatography of non-volatile acids. The developing solvent was the upper phase of a mixture of $n$-butanol, acetic acid and water (4:1: 5). Papers were developed at room temperature by the ascending method, dried and sprayed with bromphenol blue.

b) Paper chromatography of volatile acid $(7)$. The samples were spotted after conversion to ammonium salts. The developing solvent was $n$ butanol saturated with $3 \%$ aqueous solution of ammonia. Papers were developed at room temperature by the ascending method, dried and sprayed with a mixture of formalin and ethanol $(1: 5)$ with $0.05 \%(w / v)$ of bromcresol purple dissolved in and was adjusted to $\mathrm{pH} 5.0$ with $0.1 \mathrm{~N} \mathrm{NaOH}$, and observed in ammonia vapor.

c) Paper chromatography of keto acids (8). The samples were spotted after conversion to 2, 4-dinitrophenylhydrazones. The developing solvent was $n$-butanol saturated with $3 \%$ aqueous solution of ammonia. Papers were developed at room temperature by the ascending method.

5) Oxygen uptake and carbon dioxide evolution were determined by means of WARBURG manometer at $30^{\circ} \mathrm{C}$ in air. Reducing power was determined by the Somogyi's method modified by Kobayashi and TABUChI $(9)$. The spectrophotometric method of CALKINS (10) was applied in the estimation of glycolic acid. The estimation of keto acids was performed by the Shimizu's modification (11) of Friedemann-Haugen's method. Absorption spectra of 2,4-dinitrophenylhydrazone of keto acids were obtained with a SHImADZU QR-50 type spectrophotometer and a BECKMANN DK-2 type spectrophotometer.

6) Materials. The crystalline K-5-ketogluconate used as the substrate was prepared from Ca-5-ketogluconate. Glycolaldehyde synthesized from tartaric acid by the method of Fischer and TAUBE (12) was supplied by Dr. NoBuo IkEKawa of this Institute. The other sodium salts of organic acids and free acids were obtained commercially. The free acids were neutralized with $\mathrm{NaOH}$ solution prior to application. 


\section{RESULTS}

\section{1) Oxidation products of K-5-ketogluconate}

Separation of the oxidation products from K-5-ketogluconate by this organism was mainly accomplished following the procedure diagrammed in Fig. 1. After the reaction for 24 hours (the decrease of reducing power during this period was 77\%), the cells were removed from the reaction fluid by centrifugation 6,000 r.p.m. for 15 minutes and the supernatant was used for detection of reaction products.

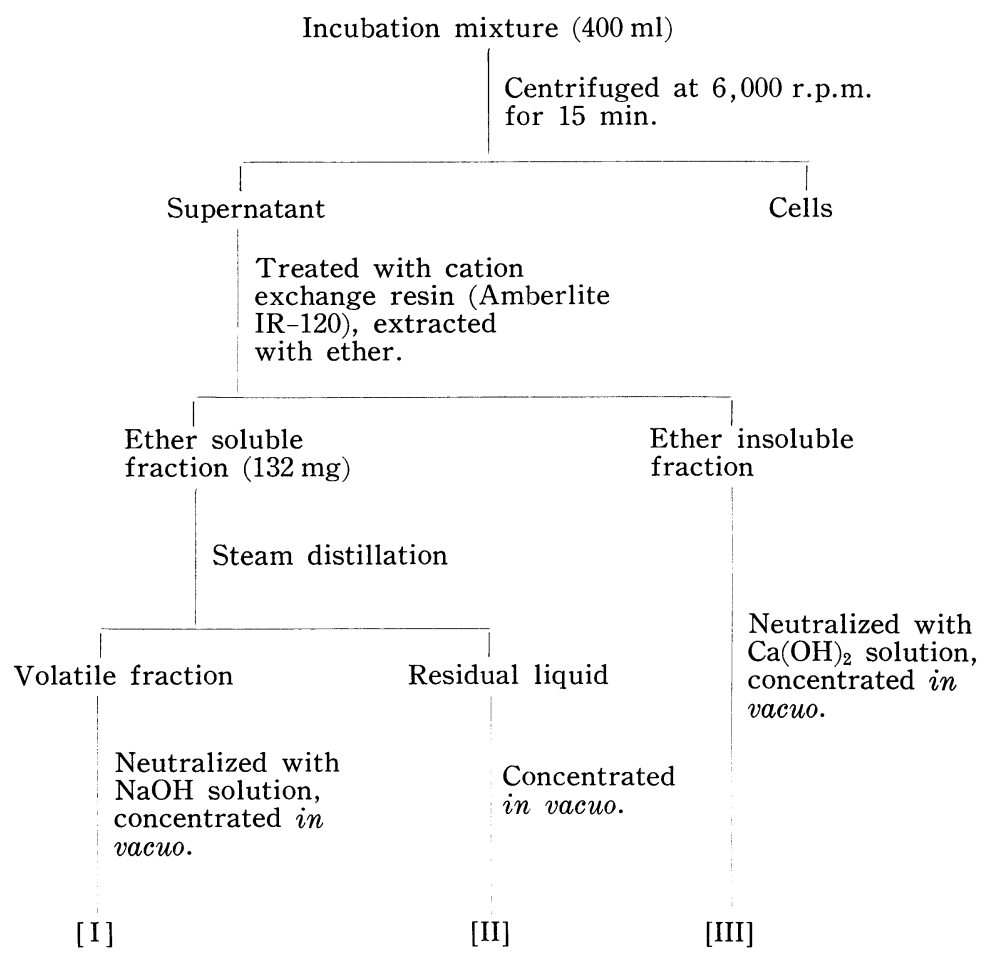

Fig. 1. The isolation procedure of oxidation products of $\mathrm{K}-5$-ketogluconate.

A) Neutral volatile fraction. In order to detect the neutral volatile substances, after adjustment of $\mathrm{pH}$ of another $50 \mathrm{ml}$ of the reaction fluid to 7.0 with $\mathrm{NaOH}$ solution, steam distillation was carried out and the distillate was examined qualitatively. (1) AGulHon's reaction, negative. (2) Davy's reaction, negative. (3) Tollen's reaction, negative. (4) GuYon's reaction, negative. Accordingly, the presence of alcohols and aldehydes was ruled out.

B) Ether soluble, volatile fraction (I). The distillate was neutralized with $\mathrm{NaOH}$ solution and concentrated in vacuo. Paper chromatography of volatile acids was applied to the concentrated liquid, and only one spot was observ- 
ed, the $R_{F}$ value of which was 0.10 . The acids possessing the same $R_{F}$ value were formic and acetic acids, the spot of which could not be separated each other. Accordingly, qualitative reaction was carried out, but formic acid could not be detected. In parallel with these reactions, another part of the incubation mixture was distilled with steam after it was acidified by sulfuric acid without ether extraction. The distillate was examined in the same manner as above, but formic acid was not detected.

Detection and identification of acetic acid. (1) It smelled of a leek when heated with arsenous acid anhydride, a result of formation of cacodyl oxide. (2) A reddish brown color appeared after the addition of $\mathrm{FeCl}_{3}$ and disappeared upon heating. (3) The iodine-lanthanum reaction was positive. (4) $p$-Bromphenacylester derivative of the volatile acid was prepared. Its melting point was identical with the authentic derivative of acetic acid and depression of melting point was not observed by admixture (m.p. $74-75^{\circ} \mathrm{C}$; uncorrected).

C) Ether soluble, non-volatile fraction (II). Paper chromatography of organic acids was applied to this fraction and three spots, except the spot of phosphoric acid which dissolved in a trace into this fraction, were observed. These three spots coincided with the spots of succinic, glycolic and $\alpha$ ketoglutaric acids respectively when these acids were developed at the same time (Fig. 2).

a) Identification of succinic acid. (1) The pillar crystals deposited were collected and recrystallized. The melting point was identical with that of succinic acid and was not depressed by admixture with an authentic sample (m.p. $183^{\circ}$; uncorrected). (2) Pyrrol reaction was positive. (3) A yellow color with green fluorescence was obtained by resorcinol-sulfuric acid reaction.

b) Detection of glycolic acid. Paper chromatography was applied and the part corresponding to glycolic acid on the chromatogram was cut off. Then, it was extracted with methanol and the solvent was removed. A beautiful red color peculiar to glycolic acid was observed by applying the color reaction of dihydroxynaphthalene (13) to the extract.

c) Identification of $\alpha$-ketoglutaric acid. (1) An $\mathrm{HCl}$ solution of 2,4-dinitrophenylhydrazine was added to the ether soluble fraction after the crystals of succinic acid were removed, and after some while, a yellow precipitate was formed. This precipitate was applied to paper chromatography of keto acids and, only at the position of $R_{F} 0.20$, was a spot observed. The $R_{F}$ value of this spot was identical with that of 2,4-dinitro-

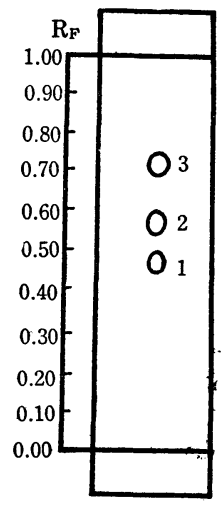

Fig. 2. Paper chromatogram of ether soluble nonvolatile fraction.

1: $\alpha$-Ketoglutaric acid $\left(R_{F}, 0.47\right)$

2: Glycolic acid $\left(R_{F}, 0.57\right)$

3: Succinic acid ( $\left.R_{F}, 0.71\right)$ 
phenylhydrazone of an authentic $\alpha$-ketoglutaric acid ( $\alpha$-KGA). (2) The precipitate obtained above was subjected to paper chromatography and the spot was extracted with $\mathrm{Na}_{2} \mathrm{CO}_{3}$ solution after cutting off. Then the extract was precipitated by acidifying with $\mathrm{HCl}$ solution. Through repetition of the above procedure, the precipitate was recrystallized and purified. The melting point of this sample was identical with that of the authentic standard and depression of melting point was not observed by admixture. (m.p. $215^{\circ} \mathrm{C}$; uncorrected). (3) Ultraviolet absorption spectra and maximum absorption of this sample coincided with those of 2,4-dinitrophenylhydrazone of an authen-

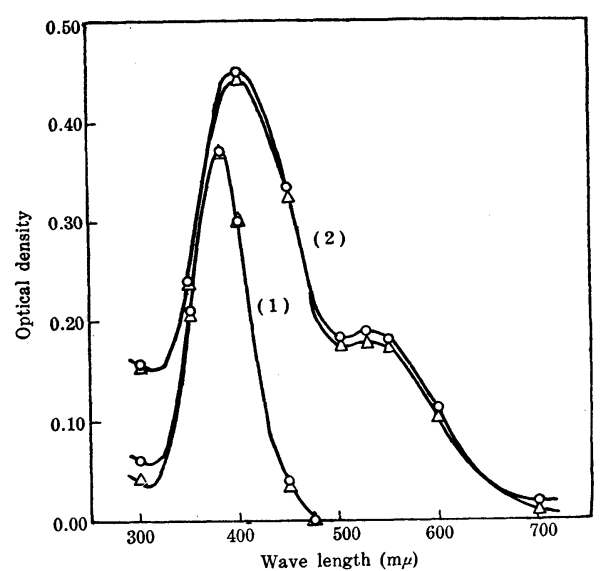

Fig. 3. Absorption spectrum of 2,4-dinitrophenylhydrazones of $\alpha$-ketoglutaric acid and the sample.

(1) Solvent: $10 \% \mathrm{Na}_{2} \mathrm{CO}_{3}$

(2) Solvent: $10 \% \mathrm{Na}_{2} \mathrm{CO}_{3}+1.25 \mathrm{~N} \mathrm{NaOH}$

$\bigcirc-\bigcirc$ : Sample

$\triangle-\triangle:$ Standard tic $\alpha$-KGA as shown in Fig. 3 and in Table 1 , respectively.

D) Ether insoluble fraction (III). A method of paper chromatography with a solvent system of water saturated $n$-butanol was applied to the sample obtained in the following manner. A suitable amount of 2,4-dinitrophenylhydrazine solution in $\mathrm{HCl}$ was added to a part of the ether insoluble fraction and kept over night. Then the yellowish red precipitate formed was gathered and dissolved in a small amount of ethyl acetate after washing with distilled water. As a result of paper chromatography of this substance, only one spot with a long tailing from the top where the $R_{F}$ value was 0.20 was observed,

Table 1. Maximum absorption of 2,4-dinitrophenylhydrazones of keto acids and the samples.

\begin{tabular}{l|c|c}
\multicolumn{1}{c|}{ Solvent } & $\alpha$-Ketoglutaric acid $(\mathrm{m} \mu)$ & Sample $(\mathrm{m} \mu)$ \\
\hline $\begin{array}{l}\text { (a) } 10 \% \mathrm{Na}_{2} \mathrm{CO}_{3} \\
\text { (b) } 10 \% \mathrm{Na}_{2} \mathrm{CO}_{3}+1.25 \mathrm{~N} \\
\mathrm{NaOH}\end{array}$ & $381-382$ & $381-383$ \\
\multicolumn{1}{c}{ Solvent } & $402-404$ & $403-404$ \\
\hline \multicolumn{2}{c}{ Pyruvic acid } & Sample $(\mathrm{m} \mu)$ \\
\hline (a) $10 \% \mathrm{Na}_{2} \mathrm{CO}_{3}$ & 370 & 370 \\
(b) $10 \% \mathrm{Na}_{2} \mathrm{CO}_{3}+1.25 \mathrm{~N}$ & 446 & 446 \\
$\mathrm{NaOH}$ & & \\
\hline
\end{tabular}


no spotsexcept this being found. This spotwas identical with the spot of 2,4-dinitrophenylhydrazone of 5-KGA appearing on the same paper chromatogram. It was therefore supposed that the precipitate obtained above might be 2,4-dinitrophenylhydrazone of 5-KGA which was supplied as the substrate and undergone no reaction during the incubation. As a result, no compounds with the carbonyl group except 5-KGA in the ether insoluble fraction could be found to react with 2,4-dinitrophenylhydrazine.

The residual part after the extraction with ether was neutralized with the solution of $\mathrm{Ca}(\mathrm{OH})_{2}$ and concentrated in vacuo, Then, in order to detect organic acids, a method of paper chromatography was applied to both the precipitate resulted from the concentration and the mother liquor, but no spot except both phosphoric acid and 5-KGA was observed.

Furthermore, in order to detect non-acidic reducing substances in the ether insoluble fraction, a part of the concentrated liquid was passed through cation exchange resin, Amberlite IR-120, to expel the calcium ion completely, and it was repassed through the anion exchange resin, Amberlite IRA-410, to expel acidic compounds. Then, the effluent obtained was concentrated in vacuo, spotted on the filter paper and applied to color reaction with both aniline hydrogen oxalate and $p$-anicidine. However, any reducing substances were not found in these experiments.

As described above, succinic, glycolic, acetic acids and $\alpha$-KGA were identified in the reaction fluid and the total amount of these acids was 132 $\mathrm{mg}$ in $400 \mathrm{ml}$ of the incubation mixture, 5 per cent smaller than that of 5 KGA used as the substrate.

Further investigations to follow were made in order to verify whether or not these organic acids detected in the reaction fluid were produced from 5 -KGA by the enzymes of this organism, or by autoxidation of 5-KGA during the incubation period, or during the isolating process of these compounds, and also whether from the degradation of a trace of glucose added or of the cells. Three kinds of solutions described above ((a), (b) and (c)) were incubated at $30^{\circ} \mathrm{C}$ under shaking for 24 hours. After the incubation, they were treated in exactly the same manner as described above. Then, the sample of the ether soluble fraction was applied to paper chromatography of organic acids. As for the results obtained from the experiments conducted at room temperature in winter, three spots corresponding to succinic, glycolic acid and $\alpha$-KGA besides phosphoric acid were found in the case of the sample obtained from solution (a), as evidenced in Fig. 2, but could not be detected in solutions, (b) and (c). In the experiment conducted in summer, however, a spot corresponding to glycolic acid was found in a sample taken from solution (c). Thus it was presumed that under the unfavorable condition, 5-KGA which had undergone no reaction might be oxidized spontaneously during the separation process of products in the incubation mixture resulting in the production of glycolic acid. When violet filter paper sprayed with alcohol solution of bromphenol blue was applied to the top of the flasks containing the ether 
soluble fraction to detect acetic acid, a yellow color appeared on the paper in sample (a) but not in samples (b) and (c). This indicates the fact that succinic, glycolic, acetic acids and $\alpha$-KGA are metabolic products of 5-KGA produced by the enzymes of $A$. suboxydans.

E) Identification of pyruvic acid. An amount of $400 \mathrm{ml}$ of solution (a) described above, divided into eight $500 \mathrm{ml}$ shake flasks (each flask containing $50 \mathrm{ml}$ of the solution) was aerobically incubated at $30^{\circ} \mathrm{C}$ on a reciprocating shaker for 6 hours. After the reducing power in the reaction mixture decreased to $50 \sim 55 \%$, reaction ceased, where the solution was centrifuged to remove the cells. To the supernatant was added $100 \mathrm{ml}$ of 2,4-dinitrophenylhydrazine solution in $\mathrm{HCl}$ and allowed to stand at room temperature for 30 minutes. The solution was extracted with xylol. In this xylol layer, 2,4dinitrophenylhydrazone of pyruvic acid* could be detected by means of paper chromatography. Then, the xylol soluble 2,4-dinitrophenylhydrazones were re-extracted with 10 per cent $\mathrm{NaHCO}_{3}$ solution, acidified immediately with $\mathrm{HCl}$ solution (1:1), and finally extracted with ethyl acetate. Ethyl acetate was evaporated and the residue was again dissolved in a small quantity of ethyl acetate and it was spotted in line $2.5 \mathrm{~cm}$ off the margin of a filter

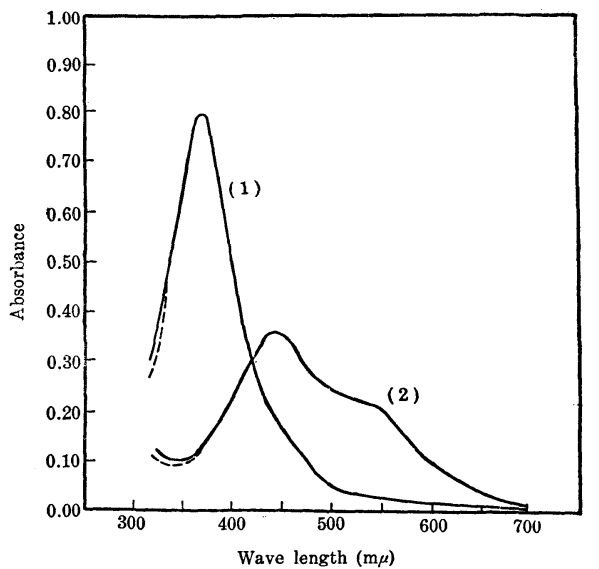

Fig. 4. Absorption spectrum of 2,4-dinitrophenylhydrazones of pyruvic acid andthe sample.

(1) Solvent: 10\% $\mathrm{Na}_{2} \mathrm{CO}_{3}$

(2) Solvent: $10 \% \mathrm{Na}_{2} \mathrm{CO}_{3}+1.25 \mathrm{~N} \mathrm{NaOH}$

- $:$ Sample

-..: Standard paper (Tôyô filter paper No. 50, $40 \times 40 \mathrm{~cm}$ ). The paper was developed by the method described above. After developing and drying, the part of the paper bearing the spot of 2,4-dinitrophenylhydrazone of pyruvic acid was cut off and extracted with 10 per cent $\mathrm{NaHCO}_{3}$ solution, acidified at once with $\mathrm{HCl}$ solution, reextracted with ethyl acetate and finally ethyl acetate was evaporated. The paper chromatogram of this residual substance gave the spots identical to those of the 2,4-dinitrophenylhydrazone of pure authentic pyruvic acid. And then the thick spot was cut off and eluted with 10 per cent $\mathrm{Na}_{2}$ $\mathrm{CO}_{3}$ solution. The absorption spectrum of this solution obtained through a Beckman DK-2 type spectrophotometer, showed the same figure and the same maximum absorption

* Paper chromatogram of 2, 4-dinitrophenylhydrazone of pyruvic acid gives two spots, for example, one of thick color with $R_{F} \quad 0.42$ and the other of thin color with $R_{F} 0,64$, 
peak as those of the 2,4-dinitrophenylhydrazone of authentic pyruvic acid. The absorption curve obtained after the above solution was alkalinized by adding the equal quantity of $1.25 \mathrm{~N} \mathrm{NaOH}$ solution showed the same figure and the same maximum absorption peak as those of pure authentic pyruvic acid similarly treated. Thus, the compound in question was ascertained to be pyruvic acid. These results were shown in Fig. 4 and Table 1.

2) Periodical changes in the amount of keto acids produced from K-5ketogluconate

The curve (1) in Fig. 5 shows the periodical changes in the amount of xylol insoluble compounds represented as $\alpha$-KGA. $\alpha$-KGA was identified as a reaction product in the experiment described above. The curve (2) shows xylol soluble 2,4-dinitrophenylhydrazone expressed in terms of pyruvic acid. As seen in the figure, the xylol insoluble compounds and the xylol soluble compounds increased in accordance with decreasing reducing power in the reaction mixture.

The amount of the xylol insoluble compounds increased and reached the maximum after 8 hours incubation. Namely, 7.95 $\mathrm{mg}$ of the xylol insoluble compounds (estimated in terms of $\alpha$ KGA) corresponding to about 3 per cent of 5-KGA supplied was accumulated in $50 \mathrm{ml}$ of the reaction mixture, while the xylol soluble compounds increased at the same time, and the maximum quantity (674 $\gamma$, estimated in terms of pyruvic acid) was obtained after 6 hours incubation.

Estimated values of xylol insoluble and soluble compounds on the solution (b) described above

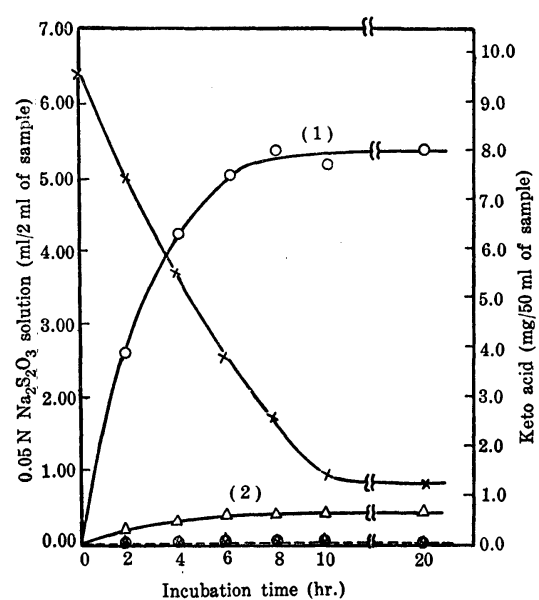

Fig. 5. Periodical changes in amount of keto acids produced from 5-ketogluconic acid.

$\bigcirc$ : Xylol insoluble 2,4-dinitrophenylhydrazones estimated as $\alpha$-ketoglutaric acid.

$\triangle$ : Xylol soluble 2,4-dinitrophenylhydrazones estimated as pyruvic acid.

$x$ : Reducing power

- : Solution (a)

--- : Solution (b)

were negligible. These results showed that reaction products with 2,4dinitrophenylhydrazine were not due to a small amount of added glucose or to the cell materials.

In order to clarify the nature of the reaction products with 2,4-dinitrophenylhydrazine, the xylol insoluble and soluble compounds were investigated by means of paper chromatography on each fluid withdrawn from 
the reaction mixture at different time intervals. As shown in Fig. 6, the chromatogram of the xylol insoluble compounds gave three spots, one was a thick spot with $R_{F^{\prime}}$ value $0.06 \sim 0.07$, coinciding with the spot of 2,4dinitrophenylhydrazone of $\alpha$-KGA and the other two were very thin with $R_{F}$ values 0.93 and about 0.20 (tailing spot). It is clear that the xylol insoluble phenylhydrazone is derived mostly from that $\alpha$-KGA. Also, as

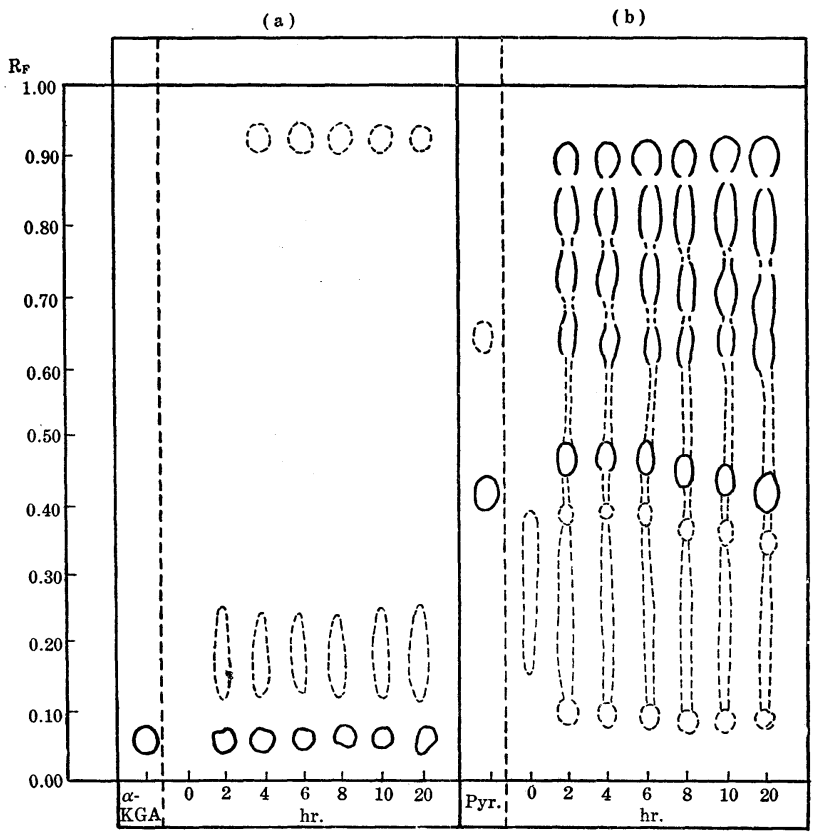

Fig. 6. Paper chromatograms of 2, 4-dinitrophenylhydrazones of oxida. tion products from 5-ketogluconic acid.

$\begin{array}{ll}\text { (a) Xylol insoluble fraction } & \text { (b) Xylol soluble fraction }\end{array}$ $\alpha$-KGA: $\alpha$-Ketoglutaric acid.

Pyr.: Pyruvic acid

hr.: Incubation time in hours

shown in Fig. 6, the chromatograms of the xylol soluble compounds gave five thick spots with $R_{F}$ values $0.42 \sim 0.47,0.63 \sim 0.64,0.73 \sim 0.76,0.81 \sim 0.82$. 0.90 (the last four spots were connected together). The spot with $R_{F}$ value $0.42 \sim 0.47$ was identical with that of 2,4-dinitrophenylhydrazone of pyruvic acid. The other spots excepting the spot of $R_{F} \quad 0.63 \sim 0.64$ were distinctly different from those of phenylhydrazone of pyruvic acid. The nature of these compounds will be reported later. 
3) Oxidation of the members of tricarboxylic acid cycle and acetic acid*

As described above, 5-KGA was oxidized by intact resting cell suspension of $A$. suboxydans and small amounts of succinic, pyruvic acids and $\alpha$ KGA were formed in the reaction mixture. These results suggest that 5KGA may be oxidized to pyruvic acid and $\mathrm{CO}_{2}$ and $\mathrm{H}_{2} \mathrm{O}$ via tricarboxylic acid cycle.

However, the dried cells of this bacteria, which are able to oxidize actively 5-KGA, did not oxidize members of tricarboxylic acid cycle, namely fumaric, succinic, malic, citric, oxalosuccinic acids and $\alpha$-KGA with the exception of oxalacetic acid. Nor was acetic acid which was detected in the oxidation products of 5 -KGA attacked by the dried cells of this organism (Table 2).

Table 2. Oxidation of the members of tricarboxylic acid cycle, acetic and glycolic acids by dried cell suspension of $A$. suboxydans.

\begin{tabular}{l|c}
\hline \multicolumn{1}{c|}{ Substrate } & Oxygen uptake at 180 minutes $(\mu l)$ \\
\hline 5-Ketogluconate & 259.0 \\
Citrate & 10.2 \\
Oxalosuccinate & 9.5 \\
$\alpha$-Ketoglutarate & 12.5 \\
Succinate & 8.0 \\
Fumalate & 16.3 \\
Malate & 17.1 \\
Oxalacetate & 42.0 \\
Acetate & 9.1 \\
Glycolate & 11.2 \\
Endogenous & 8.3 \\
\hline
\end{tabular}

The system contained: $0.8 \mathrm{ml} \mathrm{M} / 10$ phosphate buffer (pH 5.0), $5 \mu \mathrm{M}$ substrate (as sodium salt) and $30 \mathrm{mg}$ dried cells. Total volume $2.0 \mathrm{ml} . \quad 0.2 \mathrm{ml}$ $20 \% \mathrm{KOH}$ in center well. Incubated at $30^{\circ} \mathrm{C}$ in air.

\section{4) Oxidation of glycolaldehyde and glycolic acid}

Intact cells of $A$. suboxydans oxidized glycolaldehyde without $\mathrm{CO}_{2}$ evolution (Fig. 7). The amount of $\mathrm{O}_{2}$ uptake was $1 / 2$ mole for one mole of the substrate supplied. Paper chromatogram of this reaction mixture gave only one spot which was identical with that of authentic glycolic acid of $R_{F}$ value 0.57 . Estimation of glycolic acid by the CALKIN's method showed that $95 \%$ of glycolaldehyde changed to glycolic acid. Glycolic acid, one of the

* As reported previously (1), addition of a small amount of glucose was necessary for the oxidation of 5-KGA concerning this organism, but sometimes it could be oxidized without glucose and even in this case, accelerative effect of glucose was observed. The dried cells used in this experiment were the cells capable of oxidizing 5-KGA without glucose. 
Fig. 7. Oxidation of glycolaldehyde by intact cell suspension of $A$. suboxydans.

The system contained: $0.8 \mathrm{ml} \mathrm{M} / 10$ phophate buffer (pH 5.0), $5 \mu \mathrm{M}$ glycolaldehyde in $0.7 \mathrm{ml}$ distilled water and $0.5 \mathrm{ml}$ cell suspension $(2 \mathrm{mg}$ dry weight). Total volume, $2.0 \mathrm{ml} .0 .2 \mathrm{ml}$ $20 \% \mathrm{KOH}$ in center well. Incubated at $30^{\circ} \mathrm{C}$ in air.

— $\mathrm{O}_{2}$ uptake

-.-: $\mathrm{CO}_{2}$ evolution

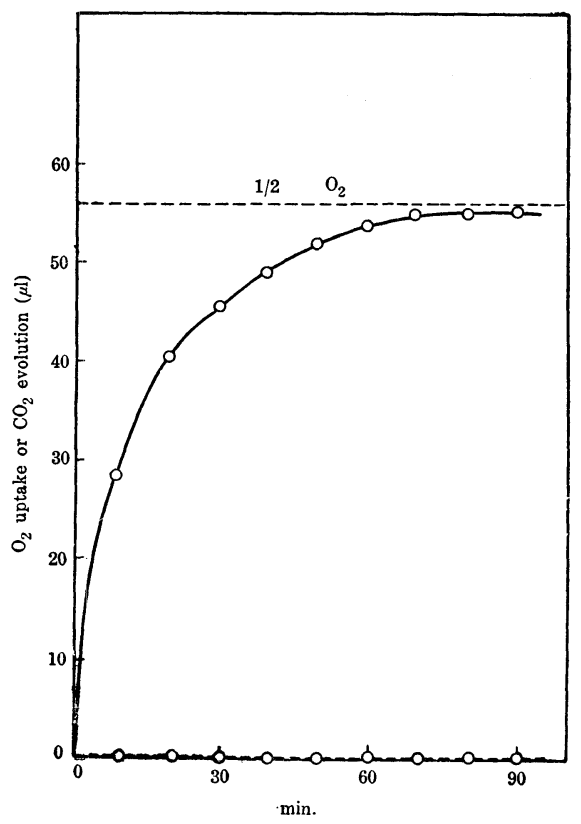

oxidation products of 5-KGA, was not attacked further (Table 2). These results agreed with the experiment reported by Fewster (2).

5) Oxidation of L-tartaric acid

According to JACKSON et al. (6), L-tartaric acid was produced from K-5ketogluconate by $P$. fluorescens, but it was not found in the oxidation products from the same substrate by $A$. suboxydans. However, in case

Table 3. Oxidation of L-tartaric acid by dried cell suspension of $A$. suboxydans.

\begin{tabular}{|c|c|c|}
\hline Substrate & Reaction time (min.) & Oxygen uptake $(\mu l)$ \\
\hline 5 -Ketogluconate $(50 \mu \mathrm{M})$ & 90 & 95.5 \\
\hline L-Tartarate $(50 \mu \mathrm{M})$ & 90 & 7.0 \\
\hline Endogenous & 90 & 2.4 \\
\hline $\begin{array}{r}5 \text {-Ketogluconate }(50 \mu \mathrm{M}) \\
\quad+\text { glucose }(0.2 \mu \mathrm{M})\end{array}$ & 40 & 215.7 \\
\hline Glucose $(0.2 \mu \mathrm{M})$ & 40 & 12.6 \\
\hline $\begin{array}{l}\text { L-Tartarate }(50 \mu \mathrm{M}) \\
\quad+\text { glucose }(0.2 \mu \mathrm{M})\end{array}$ & 90 & 17.8 \\
\hline Glucose $(0.2 \mu \mathrm{M})$ & 90 & 15.0 \\
\hline
\end{tabular}

The system contained: $0.8 \mathrm{ml} \mathrm{M} / 10$ phosphate buffer ( $\mathrm{pH} 5.0$ ), $30 \mathrm{mg}$ dried cells in $0.8 \mathrm{ml}$ distilled water, $0.2 \mathrm{ml} 50 \mu \mathrm{M} \mathrm{K}-5$-ketogluconate or K-L-tartarate (or distilled water) and $0.2 \mathrm{ml} 0.2 \mu \mathrm{M}$ glucose (or distilled water). Total volume $2.0 \mathrm{ml}$. $0.2 \mathrm{ml}$ $20 \% \mathrm{KOH}$ in center well. Incubated at $30^{\circ} \mathrm{C}$ in air. 
L-tartaric acid formed was rapidly decomposed by the cells, it was surmised this acid might not accumulate in the reaction mixture. Thus, whether or not L-tartaric acid was oxidized by the dried cells was examined. As shown in Table 3, L-tartaric acid was not attacked and this result supports FEWSTER's report (2), demonstrating that $\mathrm{D}$-, $\mathrm{L}$ - and meso-tartaric acids were not oxidized by the washed cells of $A$. suboxydans. Even when a small amount of glucose was added in the reaction system in which 5-KGA was oxidized actively, L-tartaric acid was not attacked. These results clearly indicate that this acid may not be an intermediate of 5-KGA oxidation.

\section{DISCUSSION}

It is clear from the present experiments that small quantities of acetic, succinic, pyruvic, glycolic acids and $\alpha$-KGA accumulated as oxidation products of 5 -KGA. Succinic acid and $\alpha$-KGA were known as members of the tricarboxylic acid cycle, and pyruvic acid as a precursor of these organic acids. Thus, it was presumed that 5 -KGA was converted to pyruvic acid and the latter was oxidized to $\mathrm{CO}_{2}$ and water via tricarboxylic acid cycle. If this pathway was the case, each organic acid belonging to the members of tricarboxylic acid cycle should be oxidized. However, the results of the present experiments showed that fumaric, succinic, malic, citric, oxalosuccinic acids and $\alpha$-KGA except oxalacetic acid were not attacked to any extent by dried cells of this organism while 5 -KGA was oxidized actively. The experiments with intact cells (14) and cell-free extracts (15) by KING et al. suggested that the presence of tricarboxylic acid cycle in A. suboxydans is questionable. According to these experiments, it is probable that succinic acid and $\alpha$-KGA were produced via arother pathway rather than the route of tricarboxylic acid cycle. KING et al. (16) reported the formation of acetic acid from pyruvic acid by $A$. suboxydans and they confirmed that pyruvic acid was first decarboxylated to acetaldehyde and then the latter was oxidized to acetic acid. Since, in our present experiment, pyruvic acid was found besides acetic acid in the oxidation products of $5-\mathrm{KGA}$, it may be presumed that the substrate degraded to pyruvic acid by an unknown pathway and the latter was metabolized to acetic acid through the mechanism mentioned above. Acetic acid produced was not oxidized further by dried cells as shown in Table 2. Kitos et al. (17) also ascertained that acetic acid was not oxidized either by whole cells, cell-free extract, or cell-free homogenate of this organism while the cell-free extract catalyzed the formation of acetyl-CoA and that acetic acid was incorporated in small amounts into cell lipid fractions, only in the presence of an energy source. Attemtps to detect the condensing enzyme and the route of further degradation of acetate were unsuccessful.

It was reported that tartaric acid besides 5 -and 2 -KGA was produced in the culture broth containing glucose as a substrate by $A$. suboxydans (18) and that a large amount of tartaric acid was produced in the presence of 
vanadium pentaoxide by the same culture (19). It was also reported that tartaric acid was derived from chemical oxidation of 5-KGA $(20 \sim 24)$. JACKSON et al. (6) confirmed that $\mathrm{L}$-tartaric, glycolic, formic acids and $\mathrm{CO}_{2}$ were produced from K-5-ketogluconate by Pseudomonas fluorescens. Therefore, it is supposed that tartaric acid may be an intermediary metabolite of 5-KGA by Acetobacter, though it was not detected in this investigation, and it is presumed that 5 -KGA is degraded to tartaric semialdehyde and glycoldehyde after enolization and cleavage between carbon 4 and carbon 5 of this acid, and that tartaric and glycolic acids are formed through the oxidation of these products. The results of our present experiments by $A$. suboxydans showed that glycolaldehyde was oxidized quantitatively to glycolic acid, while glycolic and tartaric acids were not oxidized at all, only a small amount of glycolic acid was formed from 5-KGA, and L-tartaric acid was not so far detected in the oxidation products. These facts suggest that although the hypothetical scheme of 5 -KGA breakdown mentioned above is a probable one in the case of oxidation by $P$. fluorescens, it may not play a significant rôle in the oxidation of 5-KGA by $A$. suboxydans if it is present. It seems likely that 5 - $\mathrm{KGA}$ is converted to 5 carbon compound and oxidized to $\mathrm{CO}_{2}$ and water via pentose cycle, which was ascertained by HAUge et al. (18) to be operative in the carbohydrate oxidation system of $A$. suboxydans.

Concerning the initial reactions of 5-KGA breakdown, it will be discussed in a report ready to be published soon.

\section{SUMMARY}

(1) It was ascertained that acetic, succinic, glycolic, pyruvic and $\alpha$ ketoglutaric acids are derived from K-5-ketogluconate as the catabolic products in the presence of a trace of glucose under aerobic condition by intact cell suspension of Acetobacter suboxydans ATCC 621.

(2) The yield of $\alpha$-ketoglutaric acid was about $3 \%$ of 5 -ketogluconic acid supplied as the substrate and the former acid produced did not undergo further oxidation.

(3) It was ascertained that dried cells of this organism which were capable of oxidizing 5-ketogluconic acid did not oxidize the members of the tricarboxylic acid cycle and related compounds except oxalacetic acid. This result suggests that tricarboxylic acid cycle may not be operative in the degradation processes of 5-ketogluconic acid.

(4) Glycolaldehyde was oxidized by this organism quantitatively but glycolic acid produced could not be oxidized further.

(5) L-Tartaric acid could not be oxidized even though a small amount of glucose was added into the reaction system.

\section{ACKNOWLEDGEMENT}

The authors wish to thank Mrs. Yoshiko Misawa (Watatsu) of this 
Institute for furnishing measurements of urtraviolet absorption spectra, Dr. Nobuo Ikekawa of this Institute for the synthesis and the supply of glycolaldehyde and Mr. Masataka Yamazaki, Fujisawa Pharmaceutical Co., Ltd. for the supply of Ca-5-ketogluconate.

\section{REFERENCES}

(1) T. Asai and H. Murooka: J. Agr. Chem. Soc. Japan, 30, 1 (1956).

(2) J. A. Fewster: Biochem. J., 69, 582 (1958).

(3) J. DeLey: Biochim. Biophys. Acta, 27, 652 (1958).

(4) J. Deley and A. H. Stouthamer: Biochim. Biophys. Acta, 34, 171 (1959).

(5) A. H. StouthameR: Doctoral Thesis, University of Utrecht (1960).

(6) R. W. Jackson, H. J. Koepsell, L. B. Lockwood, G. N. Nelson and F. H. Stodola: Inter. Congr. Biochem., Abstr. of Communs. 1st Congr., Cambridge Engl., pp. 536 7 (1949)-

(7) R. L. ReId and M. Lederer: Biochem. J. 50, 60 (1951).

(8) D. Cavallini, N. Frontali and G. Toschi: Nature, 163, 568 (1949).

(9) T. Kobayashi and T. TabUChi: J. Agr. Chem. Soc. Japan, 23, 171 (1954).

(10) V. P. Calkins: Anal. Chem., 15, 762 (1943).

(11) T. Shimizu: J. Biochem., 37, 421 (1950).

(12) H. O. L. Fischer and C. TAUbe: Ber., 60, 1707 (1927).

(13) F. Feigl: Spot tests in Organic Analysis, Elsevier Publishing Company, New York, p. 249 (1954).

(14) T. E. KING and V. H. Chelduin: J. Biol. Chem., 220, 177 (1956).

(15) T. E. KIng and V. H. Cheldlin: Biochim. Biophys. Acta, 14, 108 (1954).

(16) T. E. King, C. J. Stewart and V. H. Cheldlin: J. Biol. Chem., 208, 821 (1954).

(17) P. A. Kitos, T. E. King and V. H. Cheldin: J. Bact., 74, 565 (1957).

(18) S. Kheshgi, H. R. Roberts and W. BUCEK: Applied Microbiol., 2, 183 (1954).

(19) J. KAMLET: U.S. Patent 2,314,831 (1943).

(20) W. E. Barch: J. Am. Chem. Soc., 55, 3653 (1933).

(21) K. Yano: J. Ferment. Techn. Japan, 23, 22 (1945).

(22) R. PASternack and E. V. Brown: U.S. Patent 2,197,021 (1940).

(23) S. Isbell and B. Holt: J. Research. Natl. Bur. Standards, 35, 433 (1945).

(24) T. E. KIng and V. H. Cheldlin: Biochim. Biophys. Acta, 14, 108 (1954). 